\title{
Diagonal Earlobe Crease, a Marker of Coronary Artery Disease: A Case Report on Frank's Sign
}

\author{
Araz Baboujian ${ }^{1}$, Prema Bezwada ${ }^{1}$, Cesar Ayala-Rodriguez ${ }^{1}$ \\ 1. Cardiology, The Brooklyn Hospital Center - Mount Sinai Heart, Brooklyn, USA
}

Corresponding author: Araz Baboujian, arazbaboujian@gmail.com

\begin{abstract}
There are various physical signs that can be used as a reliable tool to diagnose the subclinical stages of atherosclerosis, including corneal arcus, xanthelasma, and diagonal earlobe crease (DELC) or "Frank's sign". Bilateral diagonal earlobe crease has been positively correlated with coronary artery disease (CAD) and peripheral vascular disease (PVD). The presence of DELC has been identified as an independent variable for $\mathrm{CAD}$. The exact etiology is unknown and the association between the presence of DELC and coronary artery disease (CAD) still remains controversial. We report a case of a patient with bilateral DELC who was found to have remarkable non-occlusive $\mathrm{CAD}$ on diagnostic coronary angiography.
\end{abstract}

Received 01/16/2019 Review began 01/31/2019 Review ended 02/22/2019 Published 03/11/2019

๑) Copyright 2019 Baboujian et al. This is an open access article distributed under the terms of the Creative Commons Attribution License CC-BY 3.0., which permits unrestricted use, distribution, and reproduction in any medium, provided the original author and source are credited.
Categories: Cardiology, Internal Medicine, Medical Education

Keywords: case report, frank sign, diagonal earlobe crease, physical examination, coronary atery disease, peripheral vascular disease

\section{Introduction}

Frank's sign is a diagonal earlobe crease (DELC) which is a wrinkle that extends $45^{\circ}$ backward from the tragus to the auricle; it is hypothesized to be a predictor of atherosclerotic disease. This sign has been positively correlated with coronary artery disease (CAD) and peripheral vascular disease (PVD) [1-3] and was classified as an independent variable for CAD [4-5]. This correlation was first described in 1973 by an American physician, Sanders T. Frank [6]. The etiology is unclear; some studies suggested a parallel process of age-related and microvascular disease associated weakening of elastic fibers of earlobes and in coronary arteries [7].

\section{Case Presentation}

An 83-year-old male ex-smoker presented with progressive worsening of shortness of breath and dry cough for three days. His past medical history was significant for sick sinus syndrome, status-post pacemaker placement in 2014, heart failure with a reduced ejection fraction (HFrEF), hypertension, diabetes mellitus with dermopathy, rectal cancer status-post colostomy, chronic obstructive pulmonary disease (COPD), benign prostatic hypertrophy, and gout. He reported associated rhinorrhea and malaise and had been using his albuterol inhaler at home with no relief. He denied any associated chest pain, palpitations, pre-syncope, or syncope. Physical examination was remarkable for bilateral DELC, more prominent in the left ear (Figure 1). Vital signs were stable. An electrocardiogram (EKG) showed an atrial paced rhythm at 89 beats per minute. A chest $\mathrm{X}$-ray revealed clear lung fields with minimal atelectasis. Labs were pertinent for elevated troponin and D-dimer; troponin peaked at 0.58 . He was started on a heparin drip. He underwent computed tomography angiogram (CTA) of the chest which ruled out a pulmonary embolus. A transthoracic echocardiogram revealed an ejection fraction of $35 \%$ - 40\%, Grade 1 left ventricular diastolic dysfunction, and abnormal septal motion consistent with a conduction abnormality. He subsequently underwent a coronary angiogram which revealed disease of the circumflex artery with a $30 \%$ lesion in the proximal segment, a 50\% lesion in the distal segment, and a 50\% lesion in the proximal segment of the obtuse marginal artery focal lesion) (Figure 2). In view of the presence of non-obstructive CAD, he was started on appropriate medical therapy and discharged with a cardiology follow-up for medical optimization. 


\section{Cureus}
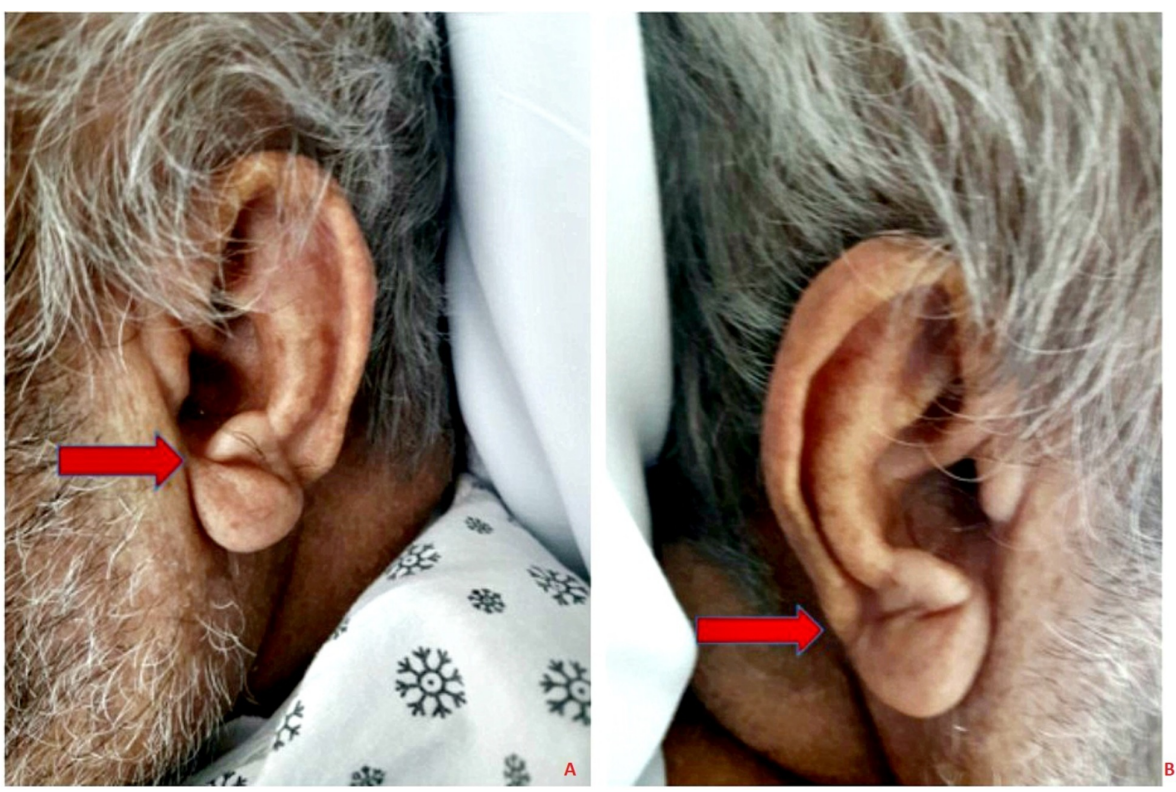

FIGURE 1: Bilateral diagonal earlobe creases as indicated by arrows

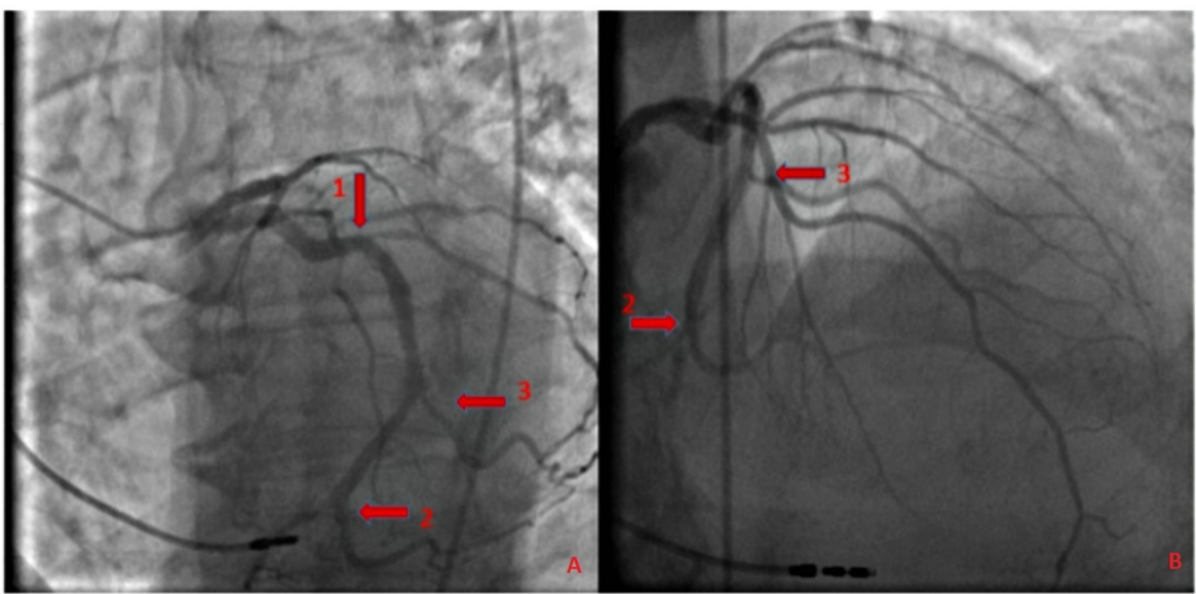

\section{FIGURE 2: Coronary angiogram}

Panels A and B: Coronary angiogram showing disease of the circumflex artery - $30 \%$ lesion in the proximal segment (arrow 1), a $50 \%$ lesion in the distal segment (arrow 2), and a $50 \%$ lesion in the proximal segment of the obtuse marginal artery (arrow 3).

\section{Discussion}

Diagonal earlobe crease (DELC), the wrinkle at $45^{\circ}$ between the auricle and the tragus, also known as Frank's sign, was first reported to be associated with CAD by Sanders T. Frank in 1973 when he noted it in 20 patients with angina [6]. From the time of its first description, studies have reported an association of DELC with the prevalence, extent, as well as the severity of CAD, and the risk of adverse cardiac events independent of commonly known risk factors, such as hypertension, diabetes, hyperlipidemia, and smoking [3-5], with bilateral complete DELC being the most severe.

Among these studies was the Copenhagen City Heart Study, a 35-year-long prospective study that reported earlobe crease, xanthelasma, and frontotemporal/crown top baldness for being independently associated with ischemic heart disease and myocardial infarction after multifactorial adjustment for well-known cardiovascular risk factors [8]. A study reported by Pasternac and Sami was conducted to evaluate the value of DELC in predicting the presence of coronary artery disease by examining the earlobes of 340 patients who underwent coronary arteriography for variable cardiac complaints. They reported that in $75.6 \%$ of those patients who had coronary artery disease, the sensitivity of the sign was $59.5 \%$, the specificity $81.9 \%$, and the positive predictive value was $91.1 \%$ [9]. The etiology of this association is unclear; some studies suggested a parallel process of age-related and microvascular disease associated weakening of elastic fibers of earlobes 
and in coronary arteries.

\section{Conclusions}

Our patient demonstrated bilateral earlobe creases in the setting of remarkable non-occlusive CAD. Recognition of this easily detectable sign by clinicians may facilitate prompt evaluation and early diagnoses of coronary atherosclerotic disease, especially in the presence of other concurrent risk factors, and help patients adapt a healthier lifestyle to help prevent the onset and progression of coronary disease.

\section{Additional Information}

\section{Disclosures}

Human subjects: Consent was obtained by all participants in this study. Twyla Tate issued approval 1369515-1. Conflicts of interest: In compliance with the ICMJE uniform disclosure form, all authors declare the following: Payment/services info: All authors have declared that no financial support was received from any organization for the submitted work. Financial relationships: All authors have declared that they have no financial relationships at present or within the previous three years with any organizations that might have an interest in the submitted work. Other relationships: All authors have declared that there are no other relationships or activities that could appear to have influenced the submitted work.

\section{References}

1. Evrengül H, Dursunoğlu D, Kaftan A, Zoghi M, Tanriverdi H, Zungur M, Kiliç M: Bilateral diagonal earlobe crease and coronary artery disease: a significant association. Dermatology. 2004, 209:271-75. $10.1159 / 000080847$

2. Korkmaz L, Ağaç MT, Acar Z, et al.: Earlobe crease may provide predictive information on asymptomatic peripheral arterial disease in patients clinically free of atherosclerotic vascular disease. Angiology. 2014, 65:303-307. 10.1177/0003319713479651

3. Çelik Ş, Erdoğan T, Gedikli Ö, Kiriș A, Erem C: Diagonal ear-lobe crease is associated with carotid intimamedia thickness in subjects free of clinical cardiovascular disease. Atherosclerosis. 2007, 192:428-31. 10.1016/i.atherosclerosis.2006.08.042

4. Qamar A, Ioannides KL, Khetarpal SA, Kiss D: Bilateral earlobe creases and coronary artery disease . Circulation. 2014, 130:92-93. 10.1161/CIRCULATIONAHA.114.009738

5. Shmilovich H, Cheng VY, Rajani R, et al.: Relation of diagonal ear lobe crease to the presence, extent, and severity of coronary artery disease determined by coronary computed tomography angiography. Am J Cardiol. 2012, 109:1283-87. 10.1016/j.amjcard.2011.12.024

6. Frank ST: Aural sign of coronary-artery disease. N Engl J Med. 1973, 289:327-28. 10.1056/NEJM197308092890622

7. Bouissou H, Pieraggi MT, Julian M, Pendaries I, Seguier J, Salvador M, Dardenne P: Value of skin biopsy in coronary insufficiency (Article in French). Arch Mal Coeur Vaiss. 1973, 66:655-60.

8. Christoffersen M, Frikke-Schmidt R, Schnohr P, Jensen GB, Nordestgaard BG, Tybjærg-Hansen A: Visible age-related signs and risk of ischemic heart disease in the general population: a prospective cohort study. Circulation. 2014, 129:990-98. 10.1161/CIRCULATIONAHA.113.001696

9. Pasternac A, Sami M: Predictive value of the ear-crease sign in coronary artery disease . Can Med Assoc J. 1982, 126:645-49. 